Article

\title{
Blue Light-Initiated Alcoholic RAFT Dispersion Polymerization of Benzyl Methacrylate: A Detailed Study
}

\author{
Dongdong Liu ${ }^{1,+}$, Ruiming Zeng ${ }^{1,+}$, Hao Sun ${ }^{2}$, Li Zhang ${ }^{1,3}$ and Jianbo Tan $1,3, *$ \\ 1 Department of Polymeric Materials and Engineering, School of Materials and Energy, Guangdong \\ University of Technology, Guangzhou 510006, China \\ 2 Department of Chemistry, Northwestern University, Evanston, IL 60208, USA \\ 3 Guangdong Provincial Key Laboratory of Functional Soft Condensed Matter, Guangzhou 510006, China \\ * Correspondence: tanjianbo@gdut.edu.cn \\ + These authors contributed equally to this work.
}

Received: 19 May 2019; Accepted: 9 July 2019; Published: 1 August 2019

\begin{abstract}
Blue light-initiated alcoholic reversible addition-fragmentation chain transfer (RAFT) dispersion polymerization of benzyl methacrylate (BzMA) using bis (acyl) phosphane oxide (BAPO) as the photo-initiator is developed to prepare diblock copolymer nano-objects. High monomer conversion (95\%) was achieved within $2 \mathrm{~h}$ of blue light irradiation in an isopropanol/water mixture. Effects of solvent, light intensity, and reaction temperature on the polymerization kinetics were evaluated. Finally, the effect of reaction temperature on the morphologies of diblock copolymer nano-objects was investigated and two morphological phase diagrams were constructed at 25 and $70^{\circ} \mathrm{C}$. Transmission electron microscopy (TEM) measurement confirmed that increasing the reaction temperature promoted the evolution of higher order morphology. We believe this study will provide more mechanistic insights into alcoholic RAFT dispersion polymerization for the creation of diblock copolymer nano-objects with well-defined structures.
\end{abstract}

Keywords: alcoholic RAFT dispersion polymerization; blue light; diblock copolymer nano-objects

\section{Introduction}

Solution self-assembly of block copolymers is a versatile method to produce block copolymer nano-objects with different morphologies, including spheres, cylindrical micelles, vesicles, lamellae etc., [1-3]. These block copolymer nano-objects have diverse applications in nanoreactors, catalysis, bioimaging, and drug delivery [4-7]. However, the solution self-assembly of block copolymers is usually conducted at diluted block copolymer concentrations $(<1 \%)$. Moreover, additional post-polymerization processing ( $\mathrm{pH}$ change, solvent switch) is usually required [1]. These features restrict the production of block copolymer nano-objects in a large scale by solution self-assembly, which is not beneficial for industrial applications.

In recent years, polymerization-induced self-assembly (PISA) via reversible addition-fragmentation chain transfer (RAFT) dispersion polymerization has become a robust method for the production of block copolymer nano-objects with various morphologies at high solids $(10-50 \%)$ [8-13]. In the case of RAFT dispersion polymerization, the monomers should be fully dissolved in the reaction medium while the generated polymers are insoluble. Block copolymer nano-objects with diverse morphologies have been produced in a variety of solvents including water [9,14-16], alcoholic solvents (alcohols or alcohol/water mixtures) [17-19], poly(ethylene glycol) [20,21], non-polar solvents [22-24], ionic liquid [25], and supercritical carbon dioxide [26]. In particular, alcoholic RAFT dispersion polymerization has become one of the most commonly studied 
PISA techniques to produce well-defined block copolymer nano-objects due to its many advantages. First, the library of monomers that are suitable for alcoholic RAFT dispersion polymerization is particularly large, allowing for the preparation of a variety of block copolymer nano-objects [27]. Second, the problem of electrostatic repulsion between highly charged stabilizers in aqueous self-assembly can be solved in alcoholic RAFT dispersion polymerization, facilitating the creation of charged block copolymer nano-objects with higher order morphologies. Third, lower surface tension of alcohol is beneficial for the deposition of polymer particles on planar substrates [18].

Several research groups have extensively studied alcoholic RAFT dispersion polymerization over the past several years. Pan and co-workers [17] reported the first alcoholic RAFT dispersion polymerization of styrene at $80{ }^{\circ} \mathrm{C}$ that can generate higher order structures. However, incomplete monomer conversions ( $70 \%$ or lower) were observed even within $48 \mathrm{~h}$. This can be explained by the fact that the reactivity of styrene is relatively low. As an alternative, the Armes Group [18] reported the alcoholic RAFT dispersion polymerization of benzyl methacrylate (BzMA) in ethanol at $70{ }^{\circ} \mathrm{C}$ and high monomer conversion ( $>98 \%$ ) was observed within $24 \mathrm{~h}$. Since then, BzMA has become one of the most popular monomers in alcoholic RAFT dispersion polymerization [27]. However, most alcoholic RAFT dispersion polymerizations of BzMA were conducted at high temperatures using a thermal initiator. This feature of alcoholic RAFT dispersion polymerization restricts the incorporation of thermally-sensitive species into block copolymer nano-objects and the development of new PISA formulations $[28,29]$. Fortunately, the recent development of photoinitiated polymerization-induced self-assembly (photo-PISA) via visible light-initiated RAFT dispersion polymerization developed by our group and others [19,30-45] has allowed the production of block copolymer nano-objects at low temperatures. The Boyer group [36] reported the first visible light-induced RAFT dispersion polymerization of BzMA in alcoholic solvents at room temperature. However, the polymerization rate is relatively low, e.g., low monomer conversions (40-70\%) were achieved within $24 \mathrm{~h}$ [36]. Moreover, acetonitrile $(\mathrm{MeCN})$, a toxic cosolvent was usually required to prepare higher order morphology [37,39].

In this contribution, blue light-initiated alcoholic RAFT dispersion polymerization of BzMA was developed to prepare well-defined diblock copolymer nano-objects at room temperature. BAPO, a commercially available photo-initiator, was employed in this case. Effects of reaction parameters including solvent, light intensity, and reaction temperature on alcoholic RAFT dispersion polymerization of BzMA were studied in detail. This study will provide more mechanistic insights into alcoholic RAFT dispersion polymerization for the production of block copolymer nano-objects.

\section{Results and Discussion}

\subsection{Synthesis of Macro-CTAs}

In this study, two macromolecular chain transfer agents (macro-CTAs) were selected to mediate the blue light-initiated alcoholic RAFT dispersion polymerization of BzMA. Monomethoxy poly (ethylene glycol) (mPEG)-based macro-CTA has been employed in aqueous or alcoholic RAFT dispersion polymerization due to its excellent solubility in both aqueous and alcoholic solvents [19,31,46]. Herein, mPEG-based macro-CTA was prepared by esterification of $\mathrm{mPEG}_{45}$ and 4-cyano-4-(dodecylsulfanylthiocarbonyl) sulfanylpentanoic acid (CDPA), denoted as $\mathrm{mPEG}_{45}$-CDPA. An esterification efficiency of $96 \%$ was confirmed by ${ }^{1} \mathrm{H}$ NMR spectroscopy (Figure S1). Poly (hydroxypropyl methacrylate)-CTA (PHPMA-CTA) was prepared by RAFT solution polymerization of HPMA in 1,4-dioxane at $70{ }^{\circ} \mathrm{C}$ using azobisisobutyronitrile (AIBN) as the initiator and CDPA as the CTA. The polymerization was quenched after $2 \mathrm{~h}$ (monomer conversion $=90 \%$ as measured by ${ }^{1} \mathrm{H}$ NMR measurement) and a mean degree of polymerization (DP) of 18 was confirmed (denoted as PHPMA $_{18}$-CDPA). Tetrahydrofuran (THF) gel permeation chromatography (GPC) gave $M_{\mathrm{n}}=4.2 \mathrm{~kg} / \mathrm{mol}$ and $M_{\mathrm{w}} / M_{\mathrm{n}}=1.15$. 


\subsection{Blue Light-Initiated Alcoholic RAFT Dispersion Polymerization of BzMA}

The macro-CTAs ( $\mathrm{mPEG}_{45}-\mathrm{CDPA}$ and $\mathrm{PHPMA}_{18}$-CDPA) were then utilized to chain extend with BzMA to produce a variety of diblock copolymer nano-objects via blue light-initiated RAFT dispersion polymerization in alcohol/water mixtures (Scheme 1). BAPO, a commercially available photo-initiator, was employed to initiate the polymerization. In this study, the molar ratio of macro-CTA and BAPO was maintained at 3.0 to ensure high polymerization rate and good controllability.

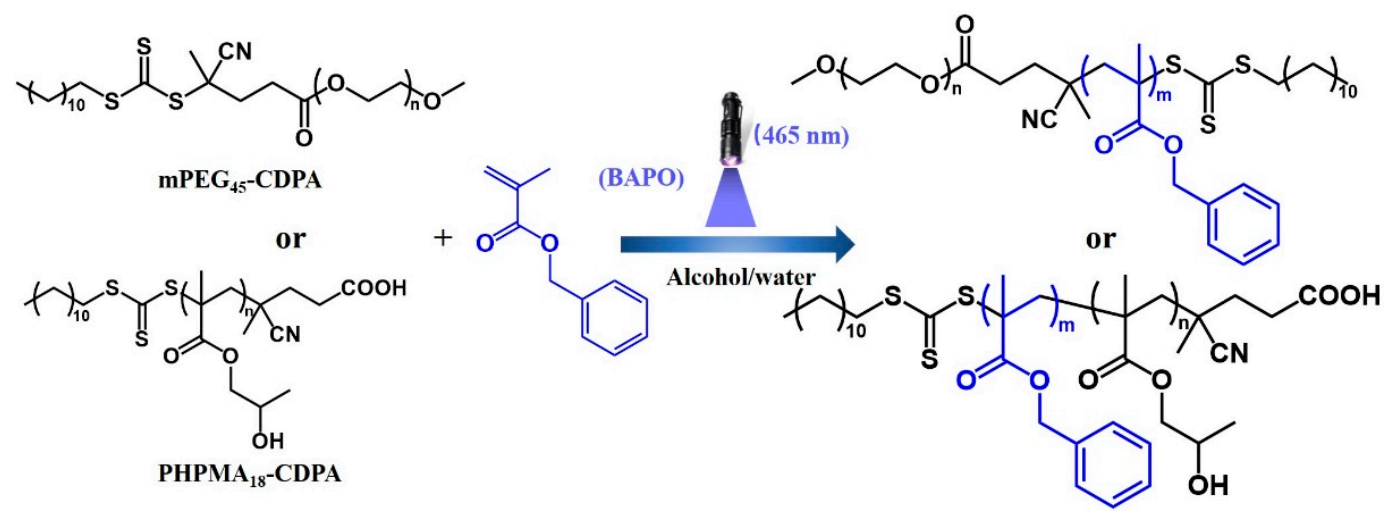

Scheme 1. Preparation of PBzMA-based diblock copolymer nano-objects via blue light-initiated alcoholic reversible addition-fragmentation chain transfer (RAFT) dispersion polymerization of BzMA with $\mathrm{mPEG}_{45}-\mathrm{CDPA}$ or PHPMA 18 -CDPA as the macro-chain transfer agents (CTA) and BAPO as the photo-initiator.

Blue light-initiated alcoholic RAFT dispersion polymerization of BzMA was first conducted in an ethanol/water mixture $(80 / 20, w / w)$ at room temperature using $\mathrm{mPEG}_{45}-\mathrm{CDPA}$ as the macro-CTA $\left(\lambda_{\max }=465 \mathrm{~nm}, 4.2 \mathrm{~mW} / \mathrm{cm}^{2}\right)$. The transparent reaction mixture became bluish and the subsequent milky white as the polymerization proceeded, indicating the in situ formation of polymer nanoparticles. However, the final monomer conversion was relatively low $(<90 \%)$ within $2 \mathrm{~h}$ of blue light irradiation. In RAFT dispersion polymerization, the monomers should be fully dissolved in the reaction medium. Therefore, the solvent used in RAFT dispersion polymerization should have a significant impact on the PISA process as well as the final morphology $[47,48]$. Kinetic studies of blue light-initiated alcoholic RAFT dispersion polymerizations of BzMA $(20 \% w / w)$ were then conducted in different alcohol/water mixtures $(80 / 20, w / w)$ using mPEG $_{45}-\mathrm{CDPA}$ as the macro-CTA (target DP of 100), as shown in Figure 1a. It is found that the blue light-initiated RAFT dispersion polymerization of BzMA conducted in isopropanol/water was significantly faster than that in ethanol/water or methanol/water. Moreover, the final monomer conversion reached up to $95 \%$ in isopropanol/water while the final monomer conversions were only $86 \%$ in both ethanol/water and methanol/water. According to the Hildebrand solubility parameters, isopropanol $\left(\delta=23.8[\mathrm{MPa}]^{1 / 2}\right)$ should be a relatively better solvent for the growing PBzMA chains $\left(\delta=15.3[\mathrm{MPa}]^{1 / 2}\right)$ than that of ethanol $\left(\delta=26.2[\mathrm{MPa}]^{1 / 2}\right)$ or methanol $(\delta=29.7$ $\left.[\mathrm{MPa}]^{1 / 2}\right)[48]$. Therefore, the PBzMA chains in isopropanol/water should have higher mobility and be easier to be swollen, leading to the relatively high monomer concentration in the particles and therefore the observed faster polymerization behavior even at high monomer conversions. The change of alcoholic solvent should have little effect on the polymerization rate in the homogenous polymerization stage, since the formed $\mathrm{mPEG}_{45}$-PBzMA diblock copolymers are fully dissolved in the solvent. This can be further confirmed by the semilogarithmic plots. Two distinct regimes were observed in all cases (Figure $1 \mathrm{~b}$ ), which correspond to the homogenous polymerization and heterogenous polymerization. The polymerization rate was almost identical in each case during the homogenous polymerization stage. During the heterogenous polymerization stage, the polymerization mainly occurred inside the monomer-swollen micelles, leading to the increase in polymerization rate. In the following experiments, most polymerizations were conducted in isopropanol/water $(80 / 20, w / w)$ unless otherwise stated. 

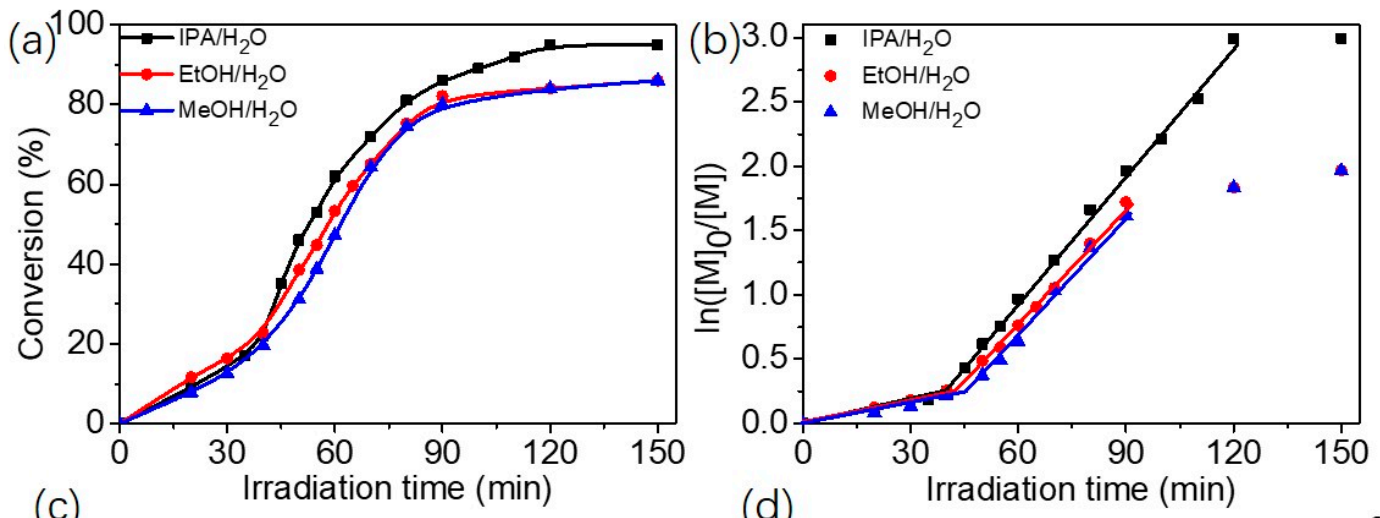

(c)
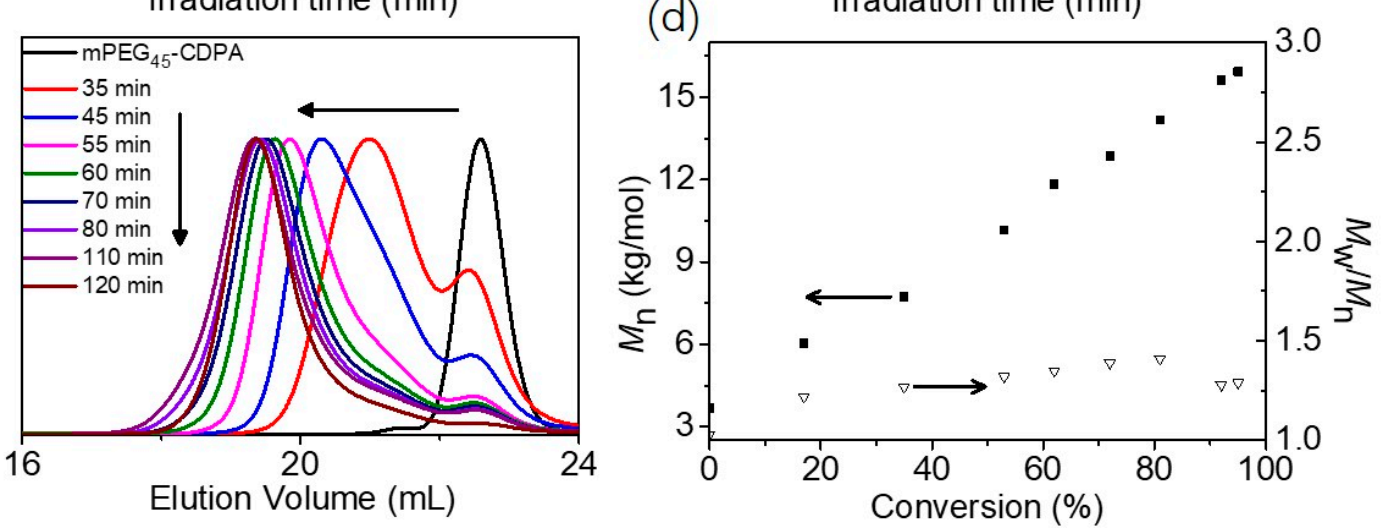

Figure 1. (a) Polymerization kinetics for blue light-initiated alcoholic RAFT dispersion polymerization of $\mathrm{mPEG}_{45}-\mathrm{PBzMA}_{100}$ with $20 \%$ w/w BzMA in different solvents. (b) Plots of $\ln \left([\mathrm{M}]_{0} /[\mathrm{M}]\right)$ versus irradiation time according to the data in Figure 1a. (c) THF GPC traces of $\mathrm{mPEG}_{45}-\mathrm{CDPA}$ and diblock copolymers prepared via blue light-initiated alcoholic RAFT dispersion polymerization of $\mathrm{mPEG}_{45}-\mathrm{PBzMA}_{100}$ with 20\% w/w BzMA in isopropanol/water $(80 / 20, w / w)$. (d) Evolution of $M_{\mathrm{n}}$ and $M_{\mathrm{w}} / M_{\mathrm{n}}$ with monomer conversion for the blue light-initiated alcoholic RAFT dispersion polymerization of $\mathrm{mPEG}_{45}-\mathrm{PBzMA}_{100}$ with $20 \% w / w \mathrm{BzMA}$ in isopropanol/water $(80 / 20, w / w)$. All experiments were carried out at room temperature.

Samples withdrawn during the kinetic study of blue light-initiated RAFT dispersion polymerization in isopropanol/water were also characterized by THF GPC. Figure 1c shows corresponding GPC traces of the samples and two GPC peaks were found in the GPC trace at the beginning of the polymerization (e.g., $35 \mathrm{~min}$ ). The right peak should correspond to the unreacted mPEG $_{45}-\mathrm{CDPA}$, while the left peak should correspond to the formed $\mathrm{mPEG}_{45}-\mathrm{PBzMA}_{n}$ diblock copolymer. As the polymerization proceeded, the left peak decreases gradually and the right peak shifts to lower elution volume. Near unimodal GPC trace was observed for the final sample although a small amount of $\mathrm{mPEG}_{45}$-CDPA still existed. The evolution of number-average molecular weight $\left(M_{\mathrm{n}}\right)$ with monomer conversion was linear. Moreover, narrow molecular weight distributions $\left(M_{\mathrm{w}} / M_{\mathrm{n}}<1.41\right)$ were confirmed as the polymerization proceeded. A $M_{\mathrm{W}} / M_{\mathrm{n}}$ value of 1.29 was observed for the final sample (Figure 1d). The non-zero y-intercept is attributed to the $\mathrm{mPEG}_{45}-\mathrm{CDPA}$, which has a $M_{\mathrm{n}}$ value of $3.7 \mathrm{~kg} / \mathrm{mol}$ as measured by THF GPC. These results suggest that good control was maintained in the blue light-initiated alcoholic RAFT dispersion polymerization when using BAPO as the photo-initiator.

We then explored the effect of light intensity on the blue light-initiated alcoholic RAFT dispersion polymerization of BzMA. Figure 2a shows the effect of light intensity on polymerization kinetics of blue light-initiated alcoholic RAFT dispersion polymerization of BzMA (target DP of 100, 20\% w/w BzMA). It is obvious that higher light intensity led to faster polymerization. This was also confirmed by the corresponding plots of $\ln \left([\mathrm{M}]_{0} /[\mathrm{M}]\right)$ vs. irradiation time (Figure $\left.2 b\right)$. The evolution of UV-Vis absorbance of BAPO at $370 \mathrm{~nm}$ with blue light irradiation time was also checked (Figure 2c), and 
faster decomposition of BAPO was observed at higher light density. Therefore, the higher rate of polymerization can be explained by the faster production of free radicals at higher light intensity. It should be noteworthy that the final monomer conversion was relatively low $(88 \%)$ for the strongest blue light irradiation $\left(8.0 \mathrm{~mW} / \mathrm{cm}^{2}\right)$. This may be attributed to the fast production of radicals under $8.0 \mathrm{~mW} / \mathrm{cm}^{2}$, leading to the increased probability of biradical termination. Moreover, the degradation of $\mathrm{mPEG}_{45}$-CDPA was also checked by UV-Vis spectroscopy (Figure 2d). It is shown that higher blue light intensity led to faster degradation of $\mathrm{mPEG}_{45}-\mathrm{CDPA}$, and this should also contribute to the polymerization kinetics of blue light-initiated alcoholic RAFT dispersion polymerization. THF GPC measurement confirmed that the change of light intensity had little effect on the molecular weight and molecular weight distribution on the obtained diblock copolymers (Table S1). The present method provides a facile platform to control the polymerization rate by just changing the light intensity, which is difficult for traditional thermally initiated RAFT dispersion polymerization.
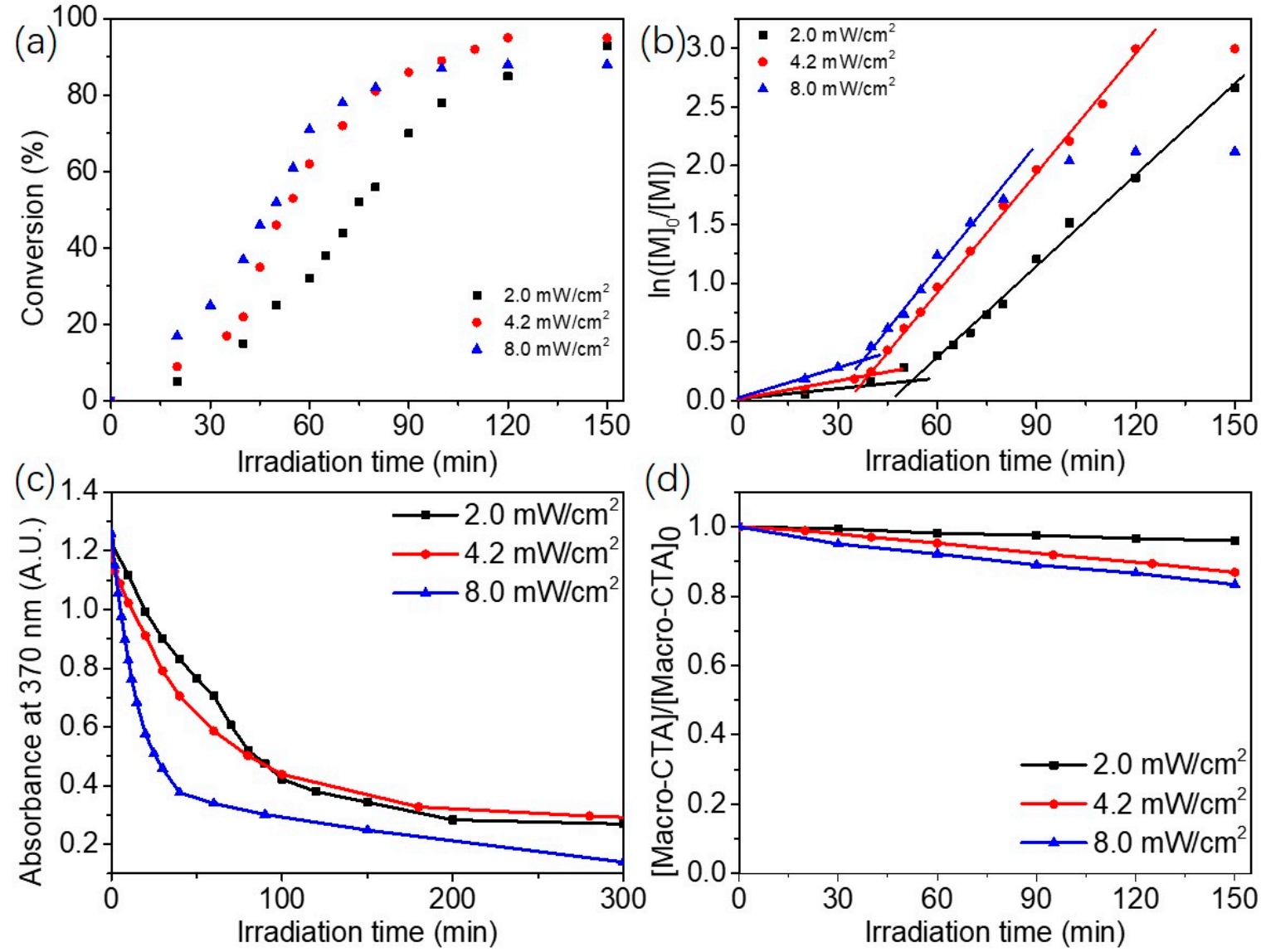

Figure 2. (a) Polymerization kinetics for blue light-initiated alcoholic RAFT dispersion polymerization of $\mathrm{mPEG}_{45}-\mathrm{PBzMA}_{100}(20 \% w / w$ BzMA $)$ at different light intensities. (b) Plots of $\ln \left([\mathrm{M}]_{0} /[\mathrm{M}]\right)$ versus irradiation time for blue light-initiated alcoholic RAFT dispersion polymerization of $\mathrm{mPEG}_{45}-\mathrm{PBzMA}_{100}$ $(20 \% w / w$ BzMA) at different light intensities. (c) Plots of normalized absorbance (at $370 \mathrm{~nm}$ ) of BAPO vs. irradiation time under $465 \mathrm{~nm}$ visible-light irradiation. (d) Degradation of $\mathrm{mPEG}_{45}-\mathrm{CDPA}$ under blue light irradiation as measured by UV-Vis spectroscopy at different light intensities.

Typically, alcoholic RAFT dispersion polymerization is conducted at high temperature (e.g., $70{ }^{\circ} \mathrm{C}$ ) via the decomposition of thermal initiators $[17,18,48]$. This feature hinders the production of polymer nano-objects that contain temperature-sensitive species (e.g., epoxy group, antibody). Moreover, the decomposition of thermal initiator is very sensitive to the change of temperature, which makes the study of effect of temperature on PISA challenging. One of the main advantages of visible light-initiated RAFT dispersion polymerization is that high monomer conversions can be achieved at 
different temperatures within a short irradiation time [49]. Therefore, the visible light-initiated RAFT dispersion polymerization provides an opportunity to investigate the effect of temperature on PISA, including polymerization kinetics and morphologies. Herein, the sole effect of temperature on blue light-initiated alcoholic RAFT dispersion polymerization of BzMA was also investigated.

Figure $3 \mathrm{a}, \mathrm{b}$ show polymerization kinetics of blue light-initiated alcoholic RAFT dispersion polymerization of $\mathrm{mPEG}_{45}-\mathrm{PBzMA}_{100}(20 \% w / w)$ at either 25 or $70^{\circ} \mathrm{C}\left(465 \mathrm{~nm}, 4.2 \mathrm{~mW} / \mathrm{cm}^{2}\right)$. It is found that the polymerization at $70{ }^{\circ} \mathrm{C}$ is significant faster than that at $25^{\circ} \mathrm{C}$. This is different from the case of alcoholic photo-PISA under $405 \mathrm{~nm}$ light irradiation [32]. To eliminate the influence of photo-initiator, the thermal stability of BAPO at 25 and $70{ }^{\circ} \mathrm{C}$ was checked. Figure $3 \mathrm{c}$ shows UV-Vis absorbance spectra of BAPO in isopropanol/water $(80 / 20, w / w)$ at either 25 or $70{ }^{\circ} \mathrm{C}$ for $1 \mathrm{~h}$. The UV-Vis absorbance spectra were almost identical, suggesting that BAPO is stable in isopropanol/water mixture at these temperatures. Therefore, we speculate the effect of temperature on the polymerization kinetics may be attributed to the photolysis of macro-RAFT agent under $465 \mathrm{~nm}$ light irradiation. The degradation degree of $\mathrm{mPEG}_{45}$-CDPA in isopropanol/water was then evaluated by monitoring the peak value at $310 \mathrm{~nm}$ under blue light irradiation $\left(465 \mathrm{~nm}, 4.2 \mathrm{~mW} / \mathrm{cm}^{2}\right)$. As shown in Figure $3 \mathrm{~d}$, around $13 \%$ $\mathrm{mPEG}_{45}$-CDPA was degraded at $25^{\circ} \mathrm{C}$ after $150 \mathrm{~min}$ of $465 \mathrm{~nm}$ light irradiation. When the temperature was increased to $70^{\circ} \mathrm{C}$, the degree of $\mathrm{mPEG}_{45}-\mathrm{CDPA}$ degradation was increased significantly to around $25 \%$ after $150 \mathrm{~min}$ of $465 \mathrm{~nm}$ light irradiation. It is well-known that the degradation of RAFT agent leads to the generation of free radicals [37]. Therefore, increasing the temperature will lead to faster blue light-initiated alcoholic RAFT dispersion polymerization.
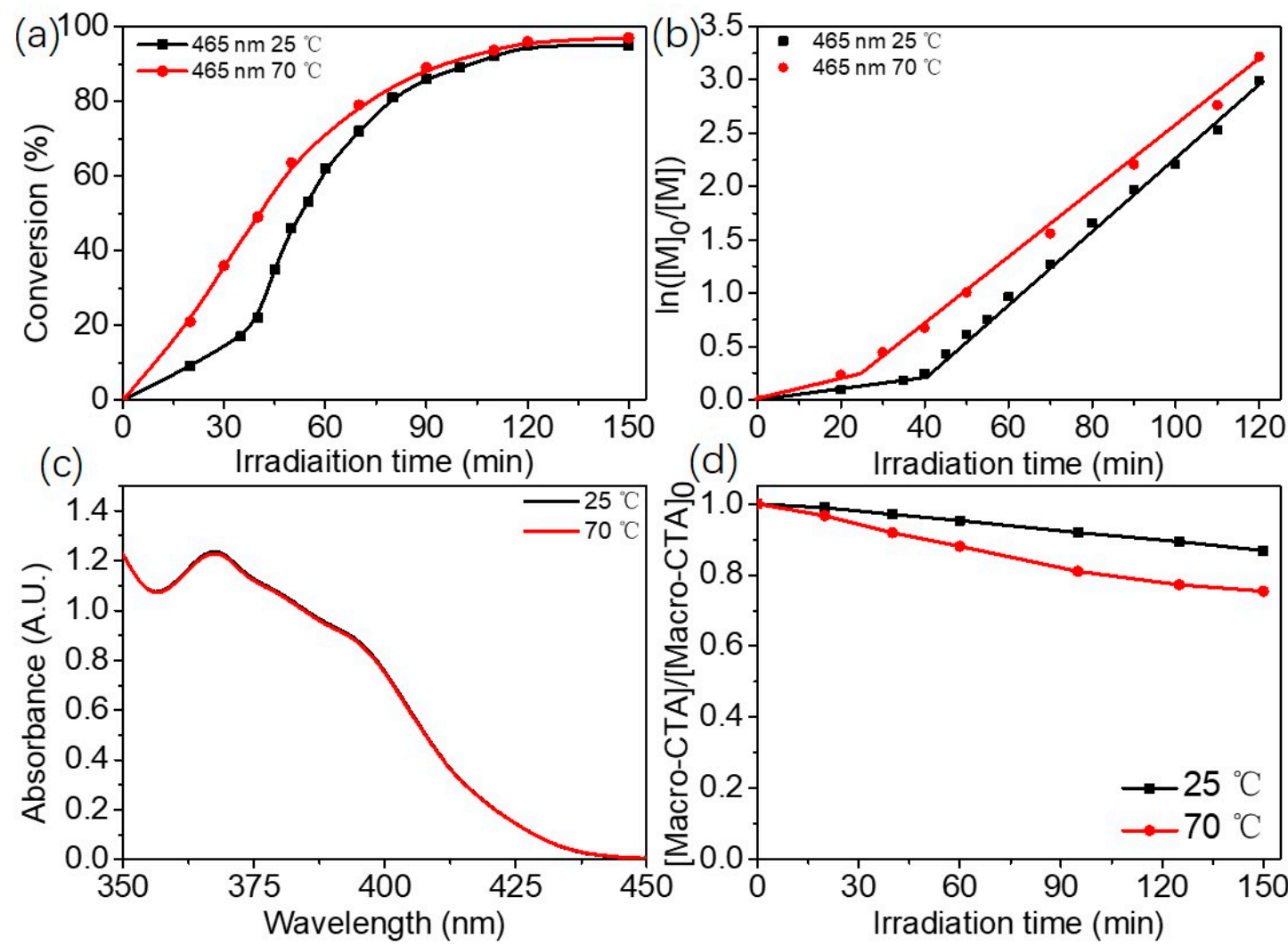

Figure 3. (a) Polymerization kinetics of blue light-initiated RAFT dispersion polymerization of $\mathrm{mPEG}_{45}-\mathrm{PBzMA}_{100}$ in isopropanol/water $(80 / 20, w / w)$ at different temperatures $(20 \% w / w \mathrm{BzMA})$. (b) Plots of $\ln \left([\mathrm{M}]_{0} /[\mathrm{M}]\right)$ versus irradiation time for blue light-initiated RAFT dispersion polymerization of $\mathrm{mPEG}_{45}-\mathrm{PBzMA}_{100}$ in isopropanol/water $(80 / 20, w / w)$ at different temperatures (20\% BzMA). (c) UV-Vis absorbance spectra of BAPO in isopropanol/water $(80 / 20, w / w)$ at different temperatures for $1 \mathrm{~h}$. (d) Degradation of $\mathrm{mPEG}_{45}-\mathrm{CDPA}$ under blue light irradiation $\left(4.2 \mathrm{~mW} / \mathrm{cm}^{2}\right)$ as determined by UV-Vis spectroscopy (at $310 \mathrm{~nm}$ ). 
The main advantage of PISA is that a variety of morphologies can be produced by changing reaction parameters, including monomer concentration, DP of the macro-CTA, and DP of the core-forming block. Figure $\mathrm{S} 4$ shows TEM images of $\mathrm{mPEG}_{45}-\mathrm{PBzMA}_{n}$ polymer nano-objects prepared by blue light-initiated alcoholic RAFT dispersion polymerization of BzMA at room temperature. Spheres were obtained at a monomer concentration of $10 \% w / w$. Further increasing the monomer concentration to $20 \% w / w$ or $30 \% w / w$ led to the creation of pure vesicles even when the DP of PBzMA was as low as 48 . In the synthesis of $\mathrm{mPEG}_{45}$-PBzMA, we were unable to obtain worm-like micelles due to the short length of $\mathrm{mPEG}_{45}$. We then attempted to use longer macro-CTA ( $\mathrm{mPEG}_{113}-\mathrm{CDPA}$ ) in blue light-initiated alcoholic RAFT dispersion polymerization. However, only spheres were obtained in all studied cases (data not shown). Although the use of mPEG-based macro-CTA is beneficial for the reproducible preparation of macro-CTA with the same DP, it is inconvenient to change the molecular weight of macro-CTA as desired since the types of commercially available PEG polymers are limited.

To demonstrate the feasibility of the present blue light-initiated RAFT dispersion polymerization, polymethacrylate prepared by RAFT polymerization should also be employed as the macro-CTA since the length of macro-CTA can be controlled conveniently. PHPMA is a polymer that has good solubility in alcoholic solvents and can be used as macro-CTA of alcoholic RAFT dispersion polymerization [50]. PHPMA $_{18}$-CDPA prepared by RAFT solution polymerization was then utilized to mediate the blue light-initiated RAFT dispersion polymerization of BzMA in an isopropanol/water (90/10, w/w) mixture. Two morphological phase diagrams of blue light-initiated alcoholic RAFT dispersion polymerization of BzMA at 25 and $70{ }^{\circ} \mathrm{C}$ were constructed by changing the DP of the PBzMA and the monomer concentration using PHPMA $_{18}-\mathrm{CDPA}$ as the macro-RAFT agent. Mean DPs of PBzMA were determined by ${ }^{1} \mathrm{H}$ NMR spectroscopy. When the reaction temperature was $25^{\circ} \mathrm{C}$ (Figure 4), a large area of spheres was found in the phase diagram at low monomer concentrations $(15 \%$ and $20 \% w / w)$. This can be explained by the reduced probability of fusion between spheres at low monomer concentrations, which has proven to be a key step for the formation of worms even vesicles. Further increasing the monomer concentration led to the formation of mixed morphologies. No pure worms or vesicles were formed at $25{ }^{\circ} \mathrm{C}$ in all studied cases. It should be noteworthy that it is possible to produce pure worms or vesicles at $25^{\circ} \mathrm{C}$ by further varying reaction conditions, but this is not the objective in the present study. In contrast, the morphological phase diagram at $70^{\circ} \mathrm{C}$ changed significantly in comparison to the one at $25^{\circ} \mathrm{C}$ (Figure 5). In this case, a large area of the pure vesicles was found, and pure worms were formed at a DP of 49 (BzMA concentration of $30 \% w / w$ ). Comparing two morphological phase diagrams, it is obvious that increasing the temperature promotes the formation of worms or vesicles in blue light-initiated alcoholic RAFT dispersion polymerization. The temperature-dependent morphological difference of the blue light-initiated alcoholic RAFT dispersion polymerization is because of two reasons. First, increasing the reaction temperature facilitates the fusion between polymer particles, which is critical for the creation of higher order morphologies. Second, the PBzMA chains have higher mobility at higher temperature, allowing the PBzMA chains to be swollen with BzMA easier, which contributes to the morphological evolution of spheres to higher order morphologies. Table S2 summarizes molecular weights and molecular weight distributions of the diblock copolymers. Similar molecular weights and molecular weight distributions were observed at 25 and $70^{\circ} \mathrm{C}$, which is consistent with the results as reported by Wenn and Junkers [51]. 

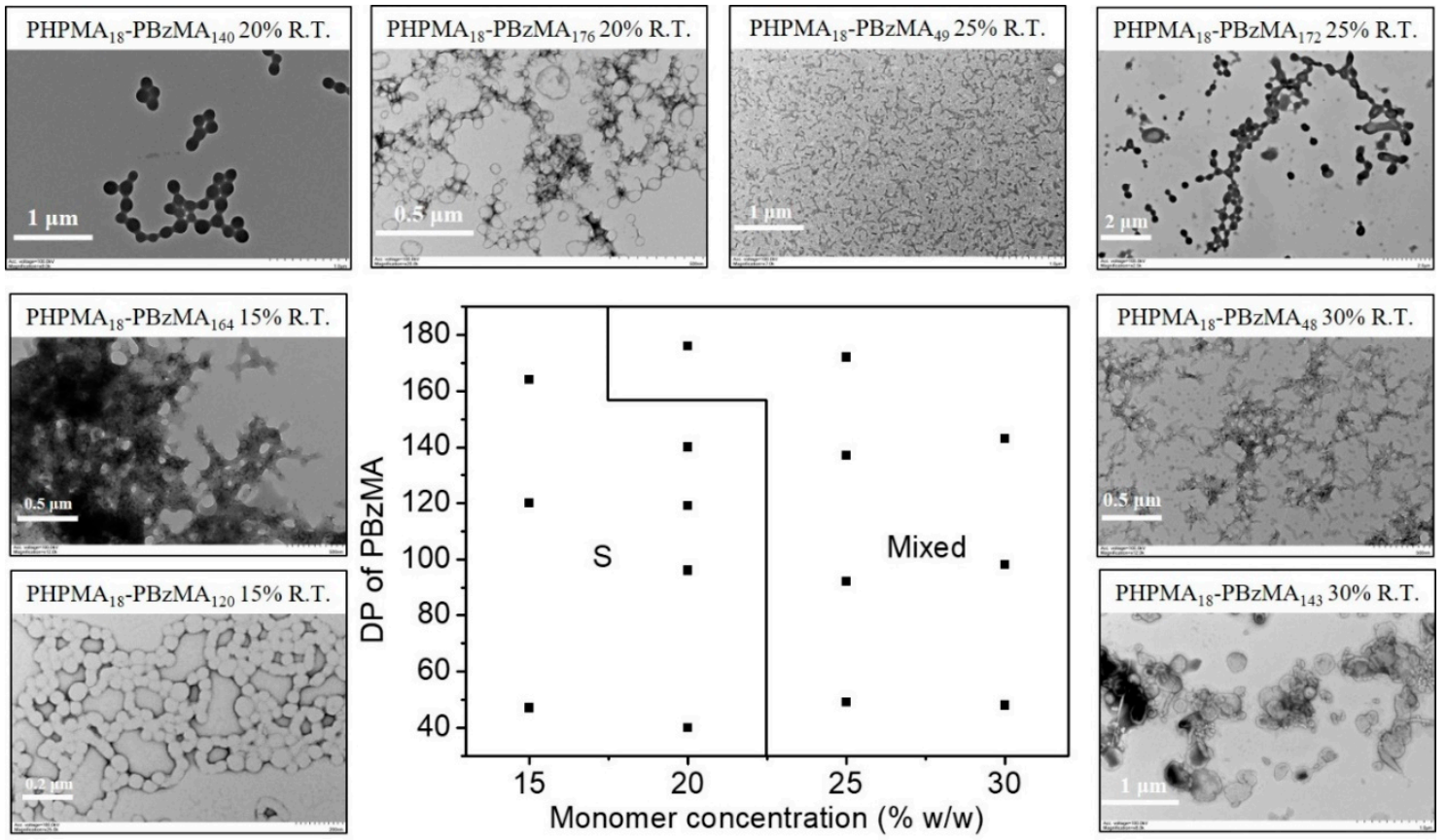

Figure 4. Representative TEM images and the morphological phase diagram for $P H P M A_{18}-P B z M A_{n}$ diblock copolymers prepared by blue light-initiated alcoholic RAFT dispersion polymerization of BzMA at $25^{\circ} \mathrm{C}$. Phase areas consist of spheres (S) and mixed morphology (Mixed).

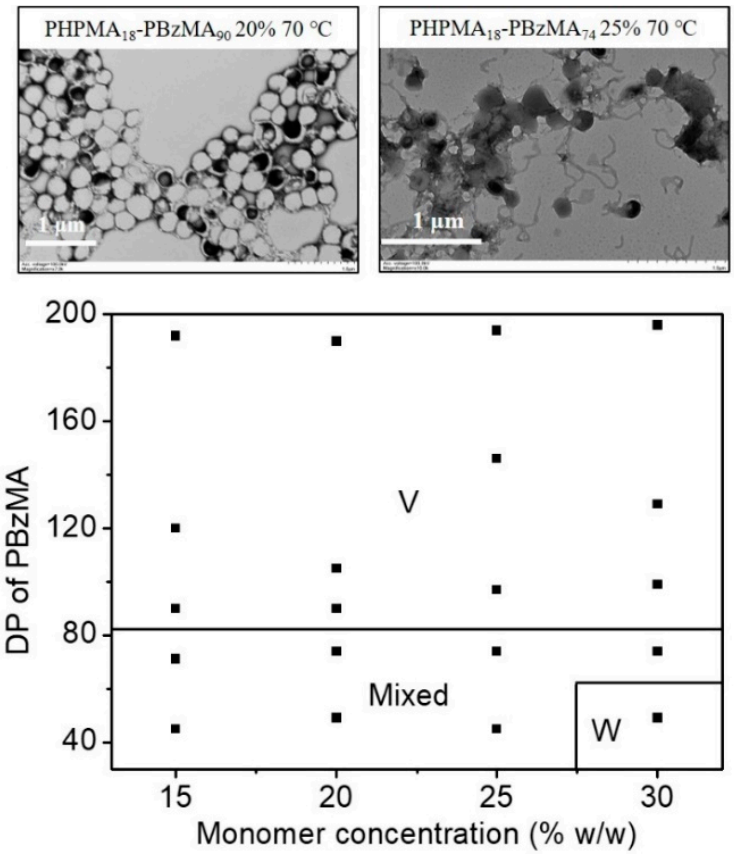
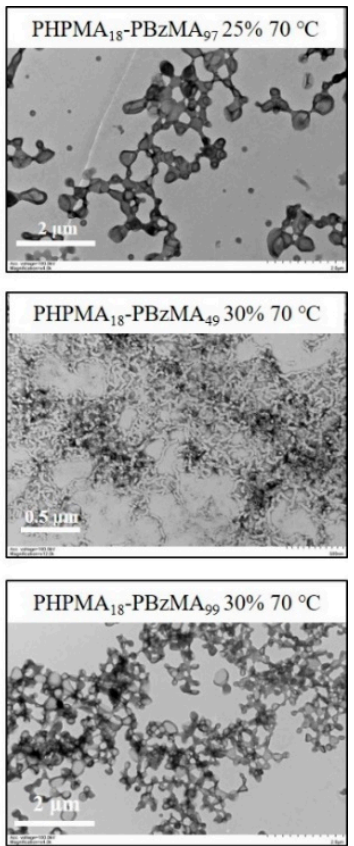

Figure 5. Representative TEM images and the morphological phase diagram for PHPMA $18-\mathrm{PBzMA}_{n}$ diblock copolymers prepared by blue light-initiated alcoholic RAFT dispersion polymerization of BzMA at $70{ }^{\circ} \mathrm{C}$. Phase areas consist of worms (W), mixed morphology (Mixed) and vesicles (V).

\section{Conclusions}

In conclusion, this work demonstrates a novel blue light-initiated alcoholic RAFT dispersion polymerization of BzMA using BAPO as the photo-initiator. Kinetic studies indicated that isopropanol/water mixture was a better solvent to achieve higher monomer conversions with higher rate of polymerization than that of ethanol/water or methanol/water. High monomer conversion 
$(>95 \%)$ was achieved within $2 \mathrm{~h}$ of blue light irradiation $\left(465 \mathrm{~nm}, 4.2 \mathrm{~mW} / \mathrm{cm}^{2}\right)$ in an isopropanol/water $(80 / 20, w / w)$ mixture. THF GPC measurement confirmed that $M_{\mathrm{n}}$ increased linearly with monomer conversion. Moreover, low polydispersities $\left(M_{\mathrm{w}} / M_{\mathrm{n}}<1.41\right)$ were observed during the polymerization, suggesting good control was maintained. Effect of light intensity on polymerization kinetics was also studied, and the rate of polymerization could be controlled easily by varying the light intensity.

Finally, the effect of temperature on the blue light-initiated alcoholic RAFT dispersion polymerization was investigated. Due to the faster degradation of $\mathrm{mPEG}_{45}-\mathrm{CDPA}$ at higher temperatures under blue light irradiation, increasing temperature led to a higher rate of polymerization in blue light-initiated alcoholic RAFT dispersion polymerization. Two morphological phase diagrams of blue light-initiated alcoholic RAFT dispersion polymerization of BzMA at 25 and $70{ }^{\circ} \mathrm{C}$ mediated by $\mathrm{PHPMA}_{18}$-CDPA were constructed. The results showed that increasing the temperature promoted the creation of higher order morphology.

Supplementary Materials: The supplementary materials are available online at http://www.mdpi.com/2073-4360/ 11/8/1284/s1.

Author Contributions: Conceptualization, L.Z. and J.T.; formal analysis, D.L. and R.Z.; data curation, D.L. and R.Z.; writing-original draft preparation, D.L. and R.Z; writing-review and editing, H.S. and J.T.; funding acquisition, L.Z. and J.T.

Funding: This research was funded by Science and Technology Planning Project of Guangdong Province (Grant 2017A010103045) and Science and Technology Program of Guangzhou (Grant 201707010420).

Acknowledgments: J.T. acknowledges the support from Pearl River Young Scholar of Guangdong.

Conflicts of Interest: The authors declare no conflict of interest.

\section{References}

1. Mai, Y.; Eisenberg, A. Self-assembly of block copolymers. Chem. Soc. Rev. 2012, 41, 5969-5985. [CrossRef] [PubMed]

2. Reynhout, I.C.; Cornelissen, J.J.L.M.; Nolte, R.J.M. Self-Assembled Architectures from Biohybrid Triblock Copolymers. J. Am. Chem. Soc. 2007, 129, 2327-2332. [CrossRef] [PubMed]

3. Kamps, A.C.; Cativo, M.H.M.; Fryd, M.; Park, S.J. Self-Assembly of Amphiphilic Conjugated Diblock Copolymers into One-Dimensional Nanoribbons. Macromolecules 2014, 47, 161-164. [CrossRef]

4. Wang, Z.; Van Oers, M.C.M.; Rutjes, F.P.J.T.; Van Hest, J.C.M. Polymersome Colloidosomes for Enzyme Catalysis in a Biphasic System. Angew. Chem. Int. Ed. 2012, 51, 10746-10750. [CrossRef] [PubMed]

5. Liu, T.; Hu, J.; Jin, Z.; Jin, F.; Liu, S. Two-Photon Ratiometric Fluorescent Mapping of Intracellular Transport Pathways of pH-Responsive Block Copolymer Micellar Nanocarriers. Adv. Healthc. Mater. 2013, 2, 1576-1581. [CrossRef] [PubMed]

6. Lee, J.S.; Feijen, J. Polymersomes for drug delivery: Design, formation and characterization. J. Control. Release 2012, 161, 473-483. [CrossRef] [PubMed]

7. Louzao, I.; Van Hest, J.C.M. Permeability Effects on the Efficiency of Antioxidant Nanoreactors. Biomacromolecules 2013, 14, 2364-2372. [CrossRef] [PubMed]

8. Tan, J.; Xu, Q.; Li, X.; He, J.; Zhang, Y.; Dai, X.; Yu, L.; Zeng, R.; Zhang, L. Enzyme-PISA: An Efficient Method for Preparing Well-Defined Polymer Nano-Objects under Mild Conditions. Macromol. Rapid Commun. 2018, 39, 1700871. [CrossRef] [PubMed]

9. Warren, N.J.; Armes, S.P. Polymerization-Induced Self-Assembly of Block Copolymer Nano-Objects via RAFT Aqueous Dispersion Polymerization. J. Am. Chem. Soc. 2014, 136, 10174-10185. [CrossRef] [PubMed]

10. Charleux, B.; Delaittre, G.; Rieger, J.; D'Agosto, F. Polymerization-Induced Self-Assembly: From Soluble Macromolecules to Block Copolymer Nano-Objects in One Step. Macromolecules 2012, 45, 6753-6765. [CrossRef]

11. Sun, J.T.; Hong, C.Y.; Pan, C.Y. Recent advances in RAFT dispersion polymerization for preparation of block copolymer aggregates. Polym. Chem. 2013, 4, 873-881. [CrossRef]

12. Zhang, X.; Boissé, S.; Zhang, W.; Beaunier, P.; D'Agosto, F.; Rieger, J.; Charleux, B. Well-Defined Amphiphilic Block Copolymers and Nano-Objects Formed in Situ via RAFT-Mediated Aqueous Emulsion Polymerization. Macromolecules 2011, 44, 4149-4158. [CrossRef] 
13. Canning, S.L.; Smith, G.N.; Armes, S.P. A Critical Appraisal of RAFT-Mediated Polymerization-Induced Self-Assembly. Macromolecules 2016, 49, 1985-2001. [CrossRef] [PubMed]

14. Zhou, W.; Qu, Q.; Xu, Y.; An, Z. Aqueous Polymerization-Induced Self-Assembly for the Synthesis of Ketone-Functionalized Nano-Objects with Low Polydispersity. ACS Macro Lett. 2015, 4, 495-499. [CrossRef]

15. Blackman, L.D.; Doncom, K.E.B.; Gibson, M.I.; O'Reilly, R.K. Comparison of photo- and thermally initiated polymerization-induced self-assembly: A lack of end group fidelity drives the formation of higher order morphologies. Polym. Chem. 2017, 8, 2860-2871. [CrossRef] [PubMed]

16. Xu, Q.; Zhang, Y.; Li, X.; He, J.; Tan, J.; Zhang, L. Enzyme catalysis-induced RAFT polymerization in water for the preparation of epoxy-functionalized triblock copolymer vesicles. Polym. Chem. 2018, 9, 4908-4916. [CrossRef]

17. Wan, W.M.; Hong, C.Y.; Pan, C.Y. One-pot synthesis of nanomaterials via RAFT polymerization induced self-assembly and morphology transition. Chem. Commun. 2009, 5883-5885. [CrossRef] [PubMed]

18. Semsarilar, M.; Jones, E.R.; Blanazs, A.; Armes, S.P. Efficient Synthesis of Sterically-Stabilized Nano-Objects via RAFT Dispersion Polymerization of Benzyl Methacrylate in Alcoholic Media. Adv. Mater. 2012, 24, 3378-3382. [CrossRef] [PubMed]

19. Tan, J.; Huang, C.; Liu, D.; Zhang, X.; Bai, Y.; Zhang, L. Alcoholic Photoinitiated Polymerization-Induced Self-Assembly (Photo-PISA): A Fast Route toward Poly(isobornyl acrylate)-Based Diblock Copolymer Nano-Objects. ACS Macro Lett. 2016, 5, 894-899. [CrossRef]

20. Gao, C.; Zhou, H.; Qu, Y.; Wang, W.; Khan, H.; Zhang, W. In Situ Synthesis of Block Copolymer Nanoassemblies via Polymerization-Induced Self-Assembly in Poly(ethylene glycol). Macromolecules 2016, 49, 3789-3798. [CrossRef]

21. Ding, Z.; Ding, M.; Gao, C.; Boyer, C.; Zhang, W. In Situ Synthesis of Coil—Coil Diblock Copolymer Nanotubes and Tubular Ag/Polymer Nanocomposites by RAFT Dispersion Polymerization in Poly(ethylene glycol). Macromolecules 2017, 50, 7593-7602. [CrossRef]

22. Fielding, L.A.; Lane, J.A.; Derry, M.J.; Mykhaylyk, O.O.; Armes, S.P. Thermo-Responsive Diblock Copolymer Worm Gels in Non-Polar Solvents. J. Am. Chem. Soc. 2014, 136, 5790-5798. [CrossRef] [PubMed]

23. Fielding, L.A.; Derry, M.J.; Ladmiral, V.; Rosselgong, J.; Rodrigues, A.M.; Ratcliffe, L.P.D.; Sugihara, S.; Armes, S.P. RAFT dispersion polymerization in non-polar solvents: Facile production of block copolymer spheres, worms and vesicles in n-alkanes. Chem. Sci. 2013, 4, 2081. [CrossRef]

24. Pei, Y.; Thurairajah, L.; Sugita, O.R.; Lowe, A.B. RAFT Dispersion Polymerization in Nonpolar Media: Polymerization of 3-Phenylpropyl Methacrylate in Tetradecane with Poly(stearyl methacrylate) Homopolymers as Macro Chain Transfer Agents. Macromolecules 2015, 48, 236-244. [CrossRef]

25. Zhang, Q.; Zhu, S. Ionic Liquids: Versatile Media for Preparation of Vesicles from Polymerization-Induced Self-Assembly. ACS Macro Lett. 2015, 4, 755-758. [CrossRef]

26. Jennings, J.; Beija, M.; Richez, A.P.; Cooper, S.D.; Mignot, P.E.; Thurecht, K.J.; Jack, K.S.; Howdle, S.M. One-Pot Synthesis of Block Copolymers in Supercritical Carbon Dioxide: A Simple Versatile Route to Nanostructured Microparticles. J. Am. Chem. Soc. 2012, 134, 4772-4781. [CrossRef]

27. Lowe, A.B. RAFT alcoholic dispersion polymerization with polymerization-induced self-assembly. Polymer 2016, 106, 161-181. [CrossRef]

28. Li, X.; Tan, J.; Xu, Q.; He, J.; Zhang, L. Photoinitiated Seeded RAFT Dispersion Polymerization: A Facile Method for the Preparation of Epoxy-Functionalized Triblock Copolymer Nano-Objects. Macromol. Rapid Commun. 2018, 39, 1800473. [CrossRef]

29. Tan, J.; Li, X.; Zeng, R.; Liu, D.; Xu, Q.; He, J.; Zhang, Y.; Dai, X.; Yu, L.; Zeng, Z.; et al. Expanding the Scope of Polymerization-Induced Self-Assembly: Z-RAFT-Mediated Photoinitiated Dispersion Polymerization. ACS Macro Lett. 2018, 7, 255-262. [CrossRef]

30. Tan, J.; Bai, Y.; Zhang, X.; Huang, C.; Liu, D.; Zhang, L. Low-Temperature Synthesis of Thermoresponsive Diblock Copolymer Nano-Objects via Aqueous Photoinitiated Polymerization-Induced Self-Assembly (Photo-PISA) Using Thermoresponsive Macro-RAFT Agents. Macromol. Rapid Commun. 2016, 37, 1434-1440. [CrossRef]

31. Tan, J.; Liu, D.; Huang, C.; Li, X.; He, J.; Xu, Q.; Zhang, L. Photoinitiated Polymerization-Induced Self-Assembly of Glycidyl Methacrylate for the Synthesis of Epoxy-Functionalized Block Copolymer Nano-Objects. Macromol. Rapid Commun. 2017, 38, 1700195. [CrossRef] [PubMed] 
32. Tan, J.; He, J.; Li, X.; Xu, Q.; Huang, C.; Liu, D.; Zhang, L. Rapid synthesis of well-defined all-acrylic diblock copolymer nano-objects via alcoholic photoinitiated polymerization-induced self-assembly (photo-PISA). Polym. Chem. 2017, 8, 6853-6864. [CrossRef]

33. Tan, J.; Xu, Q.; Zhang, Y.; Huang, C.; Li, X.; He, J.; Zhang, L. Room Temperature Synthesis of Self-Assembled $\mathrm{AB} / \mathrm{B}$ and $\mathrm{ABC} / \mathrm{BC}$ Blends by Photoinitiated Polymerization-Induced Self-Assembly (Photo-PISA) in Water. Macromolecules 2018, 51, 7396-7406. [CrossRef]

34. He, J.; Xu, Q.; Tan, J.; Zhang, L. Ketone-Functionalized Polymer Nano-Objects Prepared via Photoinitiated Polymerization-Induced Self-Assembly (Photo-PISA) Using a Poly(diacetone acrylamide)-Based Macro-RAFT Agent. Macromol. Rapid Commun. 2019, 40, 1800296. [CrossRef]

35. Tan, J.; Dai, X.; Zhang, Y.; Yu, L.; Sun, H.; Zhang, L. Photoinitiated Polymerization-Induced Self-Assembly via Visible Light-Induced RAFT-Mediated Emulsion Polymerization. ACS Macro Lett. 2019, 8, $205-212$. [CrossRef]

36. Yeow, J.; Xu, J.; Boyer, C. Polymerization-Induced Self-Assembly Using Visible Light Mediated Photoinduced Electron Transfer-Reversible Addition-Fragmentation Chain Transfer Polymerization. ACS Macro Lett. 2015, 4, 984-990. [CrossRef]

37. Yeow, J.; Sugita, O.R.; Boyer, C. Visible Light-Mediated Polymerization-Induced Self-Assembly in the Absence of External Catalyst or Initiator. ACS Macro Lett. 2016, 5, 558-564. [CrossRef]

38. Ng, G.; Yeow, J.; Xu, J.; Boyer, C. Application of oxygen tolerant PET-RAFT to polymerization-induced self-assembly. Polym. Chem. 2017, 8, 2841-2851. [CrossRef]

39. Yeow, J.; Shanmugam, S.; Corrigan, N.; Kuchel, R.P.; Xu, J.; Boyer, C. A Polymerization-Induced Self-Assembly Approach to Nanoparticles Loaded with Singlet Oxygen Generators. Macromolecules 2016, 49, 7277-7285. [CrossRef]

40. Ding, Y.; Cai, M.; Cui, Z.; Huang, L.; Wang, L.; Lu, X.; Cai, Y. Synthesis of Low-Dimensional Polyion Complex Nanomaterials via Polymerization-Induced Electrostatic Self-Assembly. Angew. Chem. Int. Ed. 2018, 57, 1053-1056. [CrossRef]

41. Jiang, Y.; Xu, N.; Han, J.; Yu, Q.; Guo, L.; Gao, P.; Lu, X.; Cai, Y. The direct synthesis of interface-decorated reactive block copolymer nanoparticles via polymerisation-induced self-assembly. Polym. Chem. 2015, 6, 4955-4965. [CrossRef]

42. Ma, Y.; Gao, P.; Ding, Y.; Huang, L.; Wang, L.; Lu, X.; Cai, Y. Visible Light Initiated Thermoresponsive Aqueous Dispersion Polymerization-Induced Self-Assembly. Macromolecules 2019, 52, 1033-1041. [CrossRef]

43. Blackman, L.D.; Varlas, S.; Arno, M.C.; Fayter, A.; Gibson, M.I.; O’Reilly, R.K. Permeable Protein-Loaded Polymersome Cascade Nanoreactors by Polymerization-Induced Self-Assembly. ACS Macro Lett. 2017, 6, 1263-1267. [CrossRef]

44. Zaquen, N.; Azizi, W.A.A.W.; Yeow, J.; Kuchel, R.P.; Junkers, T.; Zetterlund, P.B.; Boyer, C. Alcohol-based PISA in batch and flow: Exploring the role of photoinitiators. Polym. Chem. 2019, 10, 2406-2414. [CrossRef]

45. Corrigan, N.; Yeow, J.; Judzewitsch, P.; Xu, J.; Boyer, C. Seeing the Light: Advancing Materials Chemistry through Photopolymerization. Angew. Chem. Int. Ed. 2019, 58, 5170-5189. [CrossRef]

46. Tan, J.; Huang, C.; Liu, D.; Li, X.; He, J.; Xu, Q.; Zhang, L. Polymerization-Induced Self-Assembly of Homopolymer and Diblock Copolymer: A Facile Approach for Preparing Polymer Nano-Objects with Higher-Order Morphologies. ACS Macro Lett. 2017, 6, 298-303. [CrossRef]

47. Zhang, X.; Rieger, J.; Charleux, B. Effect of the solvent composition on the morphology of nano-objects synthesized via RAFT polymerization of benzyl methacrylate in dispersed systems. Polym. Chem. 2012, 3, 1502. [CrossRef]

48. Zehm, D.; Ratcliffe, L.P.D.; Armes, S.P. Synthesis of Diblock Copolymer Nanoparticles via RAFT Alcoholic Dispersion Polymerization: Effect of Block Copolymer Composition, Molecular Weight, Copolymer Concentration, and Solvent Type on the Final Particle Morphology. Macromolecules 2013, 46, 128-139. [CrossRef]

49. Tan, J.; Liu, D.; Bai, Y.; Huang, C.; Li, X.; He, J.; Xu, Q.; Zhang, X.; Zhang, L. An insight into aqueous photoinitiated polymerization-induced self-assembly (photo-PISA) for the preparation of diblock copolymer nano-objects. Polym. Chem. 2017, 8, 1315-1327. [CrossRef] 
50. Huang, J.; Zhu, H.; Liang, H.; Lu, J. Salicylaldehyde-functionalized block copolymer nano-objects: One-pot synthesis via polymerization-induced self-assembly and their simultaneous cross-linking and fluorescence modification. Polym. Chem. 2016, 7, 4761-4770. [CrossRef]

51. Wenn, B.; Junkers, T. Continuous Microflow PhotoRAFT Polymerization. Macromolecules 2016, 49, 6888-6895. [CrossRef] 